\title{
Designing Manipulative Tools for Creative Multi and Cross-Cultural Storytelling
}

\author{
Cristina Sylla \\ University of Minho - CIEC \\ Braga, Portugal \\ cristina.sylla@ie.uminho.pt
}

\author{
Íris Susana Pires Pereira \\ University of Minho - CIED \\ Braga, Portugal \\ iris@ie.uminho.pt
}

\author{
Gabriela Sá \\ University of Minho - CIEC \\ Braga, Portugal \\ gabrielasa@mobeybou.com
}

\begin{abstract}
This paper presents and discusses the preliminary findings of a research focusing on the design and use of Mobeybou, a digital manipulative aimed at promoting the collaborative creation of multicultural and cross-cultural stories among young children. We frame the research in the wider discussion of the 21 st century skills and competencies, and present the digital manipulative as the product of a participatory design methodology. We discuss narratology, multiculturalism, embodiment and collaboration as the cornerstone ideas underpinning the design of Mobeybou. We also show how storytelling is envisioned as implying the creative use of the multicultural and multimodal information that is offered to users in the form of constraints and openended options. A pilot study, carried out with twelve 8-yearold children, has validated these design options and offered interesting insights for its further development. Here, we present the interface and discuss the feedback provided in the user study.
\end{abstract}

\section{CCS CONCEPTS}

- Human-centered computing Human computer interaction (HCI) • Human-centered computing User studies

- Human-centered computing Interaction devices

- Human-centered computing Interactive systems and tools

- Human-centered computing User interface toolkits

- Human-centered computing Interaction design process and methods

\section{Author Keywords}

Tangible Interfaces; Digital Manipulatives; Storytelling; Multiculturalism; Creativity; Collaboration.

\section{INTRODUCTION}

Creativity plays a detached role in current discussions about the essential 21 st century learning and innovation skills

Permission to make digital or hard copies of all or part of this work for personal or classroom use is granted without fee provided that copies are not made or distributed for profit or commercial advantage and that copies bear this notice and the full citation on the first page. Copyrights for components of this work owned by others than ACM must be honored. Abstracting with credit is permitted. To copy otherwise, or republish, to post on servers or to redistribute to lists, requires prior specific permission and/or a fee. Request permissions from Permissions@acm.org.

C\&C '19, June 23-26, 2019, San Diego, CA, USA

(C) 2019 Association for Computing Machinery.

ACM ISBN 978-1-4503-5917-7/19/06...\$15.00

https://doi.org/10.1145/3325480.3325501
$[2,32,35,42]$. In fact, many consider that "creativity and innovation will become the brightest stars in the constellation of $21 \mathrm{st}$ century skills" [11]. Communication and collaboration skills have also been underlined as important in problem solving, especially in overcoming cultural, geographical and language boundaries in the superdiverse workplaces and communities [48]. In other words, being a creative 21 st century citizen also demands an "increased sensitivity to cultural differences, openness to new and different ideas" [32].

\section{Reconceptualization of Literacy through Multiliteracies}

In general, a strong claim is made for a change in educational policy and curricula in order to properly teach and learn such skills [2,32,35]. Multiliteracies has become a particularly influential theoretical answer to this call [9]. Originating in the New London Group's manifesto [29], Multiliteracies offers a reconceptualization of literacy pedagogy that is strongly anchored in a renewed understanding of 'basic' literacy demands and skills. In particular, Multiliteracies assumes that the meaning making processes involved in the new 21 st century superdiverse communicative landscape are essentially multimodal [20]. It further assumes that it is the multiple modes with which we make meanings, such as still and moving images, sound, music, touch, rather than the written and oral modes of verbal language alone, that should be at the core of literacy learning in educational settings so that citizens learn how to design the demanded creative solutions [9].

\section{Creativity, Multimodality and Collaboration}

Creativity and multimodality are particularly relevant notions when it comes to thinking about the way that early childhood education can answer these transformative agenda. In fact, creativity and multimodality have long been recognized as inescapable principles undergirding children's natural learning and development $[23,49]$. Vygotsky's seminal work was fundamental in understanding that creativity builds on children's previous knowledge and experiences, which are the raw material for their creativity. Children transform such raw material through their imaginative activity, which Robinson defines as "the ability to bring to mind things that are not present to our senses" [38], he differentiates between creativity and imagination: "Creativity is a step beyond imagination: it is putting your imagination to work [38: ix]. Far from being understood as a special gift, creativity is collaborative as "creative thinking almost always builds on 
other people's ideas" [38: ix], and needs to be nurtured or triggered by constraints [8]. Children's creative work spontaneously gains form and shape through their hundred languages [24], or multiple modes, which children use to represent their creative processes. Creativity and multimodality are therefore currently reinforced as powerful dimensions in young children's education.

\section{Promoting Creativity trough Multimodal Storytelling}

Storytelling is one of the most powerful tools for children to communicate their multimodal creativity, providing opportunities for creative thinking [31], socio emotional development and social interaction, [41], offering children a "nourishing habitat for the growth of cognitive, narrative and social connectivity" [31:8]. Stories help children "to develop more sophisticated language structures, accumulate more background information and have more interest in learning to read" [28:646]. Children's storytelling is certainly an example of their creativity [7]. Being fictional (imaginary), organized as causally related events that unfold in a time and place that is non-coincident with the now of its telling, stories emerge as a promising educational strategy aiming at stimulating the creativity of the future 21 st century citizens. Furthermore, stories have other particular important roles to play regarding the demanded new set of skills. Stories are fundamental in helping children to make sense of their experience and in the development of their cognition $[5,6]$. Moreover, stories are able to promote children's curiosity about the world as well as their acknowledgement and acceptance of diversity and empathy by introducing them to unknown characters, to their lives and inner motives and feelings $[31,33,34]$. By providing a gateway to the minds of others, their emotions and experiences, stories help children to create their own identity $[31,33,34]$.

\section{Multicultural and Cross-cultural Creativity through Storytelling}

When it comes to scrutinizing the role played by stories in promoting multicultural and cross-cultural creativity, ideas are not as much clear-cut, though. While listening and reading stories seem to be strong ways of becoming acquainted with other cultures, storytelling appears to be rather challenging for children due to their restricted lived experience, which, as expected, might hinder their creative process. This is the main problem that sustains the research that we are currently developing and that we sketch in this paper. In the following, we present the design and development of Mobeybou, a tool aimed at scaffolding the creation of multicultural and cross-cultural stories among young children, and discuss the preliminary findings of a user study carried out with the tool.

\section{MOBEYBOU: A DIGITAL MANIPULATIVE FOR COLLABORATIVE AND CREATIVE MULTICULTURAL AND CROSS-CULTURAL STORYTELLING}

We start by we briefly presenting the key theoretical ideas underpinning the design of Mobeybou, combining narratology, multiculturalism, embodiment and collaboration. We also show how storytelling is envisioned as implying the creative use of the multicultural and multimodal information that is offered to users in the form of constraints and openended options. The design and development of Mobeybou follows a participatory design methodology, involving children and teachers, thus undergoing several iterations. Mobeybou aims at scaffolding young children to create digital stories by manipulating physical representations of story elements. It intends to challenge individual-mind-andmouth narrative construction transforming it into a process in which minds-hands-eyes-and-ears attune in shared embodied, multimodal and collaborative processes of narrative creation. This way, moving beyond creativity processes based on individual, mental imaginary [19]. In Mobeybou, perception and motor action, negotiation and consequential emotions are central in narrative creation. These aspects are particularly well supported by digital manipulatives [15, 16, 44, 45, 46]. Digital manipulatives [37], often also named Tangible User Interfaces (TUIs) [17], are physical representations, materials or objects with embedded computational properties that allow interacting with and manipulating digital content.

\section{Embodied, Collaborative, and Multimodal Story Creation}

The design of Mobeybou took into close consideration the main tenets of embodied and distributed cognition theories. The role of sensorimotor action in cognition is well established $[12,21,47]$ in multiple disciplines and strands of thought, from evolutionary biology and neurology to phenomenology [47]. Glenberg affirms that "all psychological processes are influenced by body morphology, sensory systems, motor systems, and emotions" [12:586]. Neurologist Frank Wilson explains the strong interdependence of hand and brain function and the evolutionary origins of that relationship: "Our fingers and hands are highly active and important means of perception and exploration, representing an access to our life world which in some cases could not have been established by any other sense modality" [47:7]. Research has also shown that besides the body, cognition is also configured by the use of resources (tools, artefacts, materials) and by our interactions with others, which are external but connected to the individual's thinking [22, 39]. Through their double function, tools can "extend our bodies" and "expand our minds" [38: vii]. The role of tools, artefacts or objects in supporting cognitive processes is well established in education, and can be traced back to visionary pedagogues such as Friedrich Fröbel [4] and Maria Montessori [26]. Robinson explains the intimate relation between tools and materials and human cognitive processes: "Creativity is a practical as well as a conceptual process: how and what we create has much to do with the tools and materials we have available, and what we make of and with them" [38: ix]. Together, these concepts have informed the design and development of Mobeybou as an embodied, multimodal and collaborative device to create stories.

\section{Narrating by Doing}

One of Mobeybou's prominent features is that, through its use, children become narrators by doing. The use of blocks implies a natural use of the body, as the children use their 
Session 8: Creativity with Kids

hands, but also their eyes and ears, to grasp, sort, divide, arrange and place the physical input devices, while manipulating the digital content and collaboratively forging new ideas. The story creation combines moving images, sounds and music with verbal language. The manipulation of the blocks stimulates children to explore different possibilities, encouraging them "to try out multiple alternatives, shift directions in the middle of the process, to take things apart and create new versions" [36]. The combination of "actional, symbolic, and sensory factors" [10] that address multisensory channels [25] creates an immersive ambient that potentially places the children into the world of fantasy, stimulating them to dive into different cultures, potentially enhancing their imagination and creativity in their narration by doing.

\section{Situating Mobeybou as a Digital Manipulative: its Original Multicultural Nature}

In a comprehensive study examining 21 tangible interfaces for storytelling from 1997 until 2015, Harley and colleagues [14] found out that research on tangible interfaces for narrative mainly focus on the technological properties of the systems; is often developed for single use cases; and seldom examines or discusses the created stories. conceptualized a framework for the analysis of storytelling activities using tangible interfaces. Their taxonomy bases on Ryan's model [40] in which the user can take four narrative positions: external-exploratory, internal-exploratory, externalontological, and internal-ontological. The externalexploratory position places the user 'outside' the story world, whereas the internal-exploratory position places the user 'inside' the story. Both positions can then be exploratory (the user explores the narrative reconstructing or rearranging events) or ontological (the user can influence the story). According to this taxonomy, the majority of the 21 analyzed TUIs require the user to perform exploratory actions from an external narrative position, this is, the user and his/her interactions exist outside the story world. These interfaces in general demand a low degree of creativity, and can decrease the degree of immersion [40]. In Mobeybou, the user's position can be both internal and external (depending on whether the user takes the role of a character) and ontological, as it allows the user to make decisions and to change the story. Mobeybou builds on and extends previous work. TOK [45], which stands for Touch, Organize, Create, is a learning environment for the construction of narratives that offers the users scenarios, characters and objects from classical stories for children. t-books [44] is a variation of the former and explores the concept of integrating physical / digital narrative elements into a book framework for guided narrative creation. Though sharing TOK's affordances, in Mobeybou imagination is ultimately triggered through the mix and remix of different cultural elements, finding the balanced combination of the constraints that inhere each element and the open-endedness of the manipulative itself.
C\&C '19 June 23-26, 2019, San Diego, CA, USA

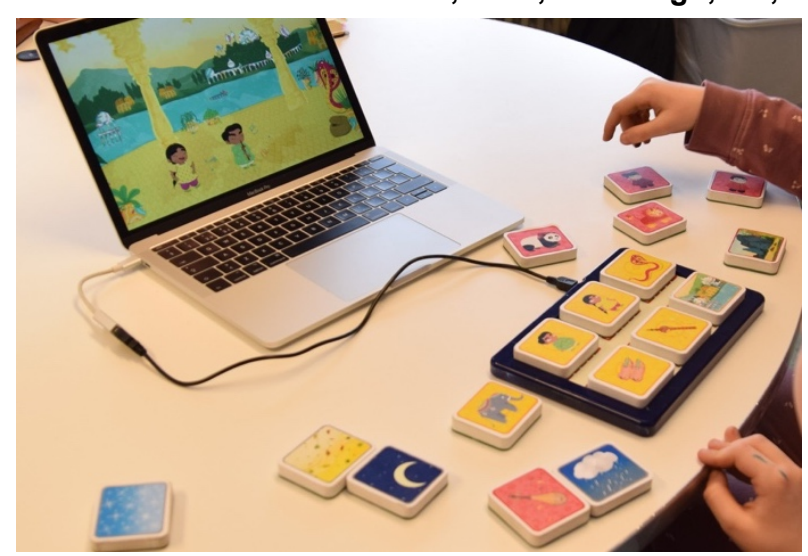

Figure 1 - Examples of the physical blocks, @photo Michael Skøtt Jensen.

\section{Description of the Tool}

Presently, Mobeybou is composed of an electronic board and various sets of physical blocks that act as interface for manipulating the digital content. The board connects to a computer or tablet via USB or Bluetooth. Each block $(4,5 \times 4,5 \times 1 \mathrm{~cm})$ has the respective visual representation on the upper face (see Figure 1). Placing a block on the board triggers its digital representation on the device's screen. When a block is removed from the board it disappears from the screen.

All the elements have specific animations that display different actions. Additionally, there are ambient and background sounds. The visual narratives unfold according to the combination of blocks that the users place on the board while they verbalize their stories. A recording button allows recording/playing children's creations.

Presently, we have developed three cultural sets (India, China and Brazil) (see Figure 2), however, we intend to extend the number of represented cultures. Each cultural set comprises: a landscape, two protagonists, an animal, an antagonist, a musical instrument and a magical object. To help the user identify the cultural set as a whole while controlling their creative combination, there are visual cues that unify the elements from a given culture, such as the repetition of patterns and a consistent color scheme.

\section{Rules and Constraints}

Except for the landscapes, (which set the stage for the narrative) and the atmospheric-blocks (rain, snow, wind, rainbow, night), all the elements behave according to a set of rules and constraints that define their actions and the relations to the other active elements (the elements that are on the board).

In their story creation with Mobeybou, the children are incentivized to find creative solutions for the situations that unfold by attending to these constraints, which they therefore must infer and understand. The underlaying constrains are given by following rules:

- The antagonists attack the protagonists;

- The animals defend the latter;

- The protagonists and the animals can join forces to defend themselves from the antagonists; 


\section{Session 8: Creativity with Kids}

- The antagonists can also join forces to attack the former;

- The musical instruments and the magical objects have magical properties and can be used by the protagonists to help the protagonists and the animals;

- When an element is defeated, the physical block needs to be lifted and placed again on the board, in order to bring it to life again.

\section{Developing a Multicultural Framework for Narrative Creation}

In the following sub-sections, we detail the rationale behind the development of the multicultural elements.

\section{Character Design}

It is challenging to empathize with the perspectives of individuals from a culture beyond our first-hand experience. This can hamper the process of designing for an international target-audience, as well as the process of representing the culture of others [13]. In Mobeybou, every depicted story element originates from an extensive research and reflection on what visuals could best identify the culture being depicted. However, we are aware that any process of representation of identities, which inevitably simplifies and homogenizes a culture - since cultures are never unitary in themselves - happens through an alienation of the complexities of the culture [3]. Stereotypical representations of a given culture leave an indelible mark on our collective brain, making it difficult to disassociate certain symbols from the culture and looking further for better and deeper representation. We acknowledge that it is beyond the scope of this work to create a comprehensive portrait of a given country or culture; instead our focus is the creation of story elements that will entice children's imagination and captivate their attention and curiosity, so that they can start a dialogue, and later learn more about the world.

India's elements derive solely from online research, which resulted in visuals that have a strong connection to the traditional and perhaps stereotyped aspects of the country. China's elements were developed after extensive online research, but also relied heavily on children's books and movies as inspiration. The final designs represent some clichés and we believe that this is mainly due to the influence of Chinese representations in pop culture and visual media. Brazil's elements were designed in collaboration with our Brazilian team members, who changed our perspective on designing the elements: it was no longer about tradition and stereotypes already seen in pop culture; it was about authenticity, contemporaneity and diversity. The visual elements have a more complex relationship with the country they are representing, making the connection less obvious. This may make it more difficult for children to identify the culture being represented; as there is no direct link between these elements and what we would usually see as representing Brazil on mass media - like football, favelas or Carnival parades.
C\&C '19 June 23-26, 2019, San Diego, CA, USA

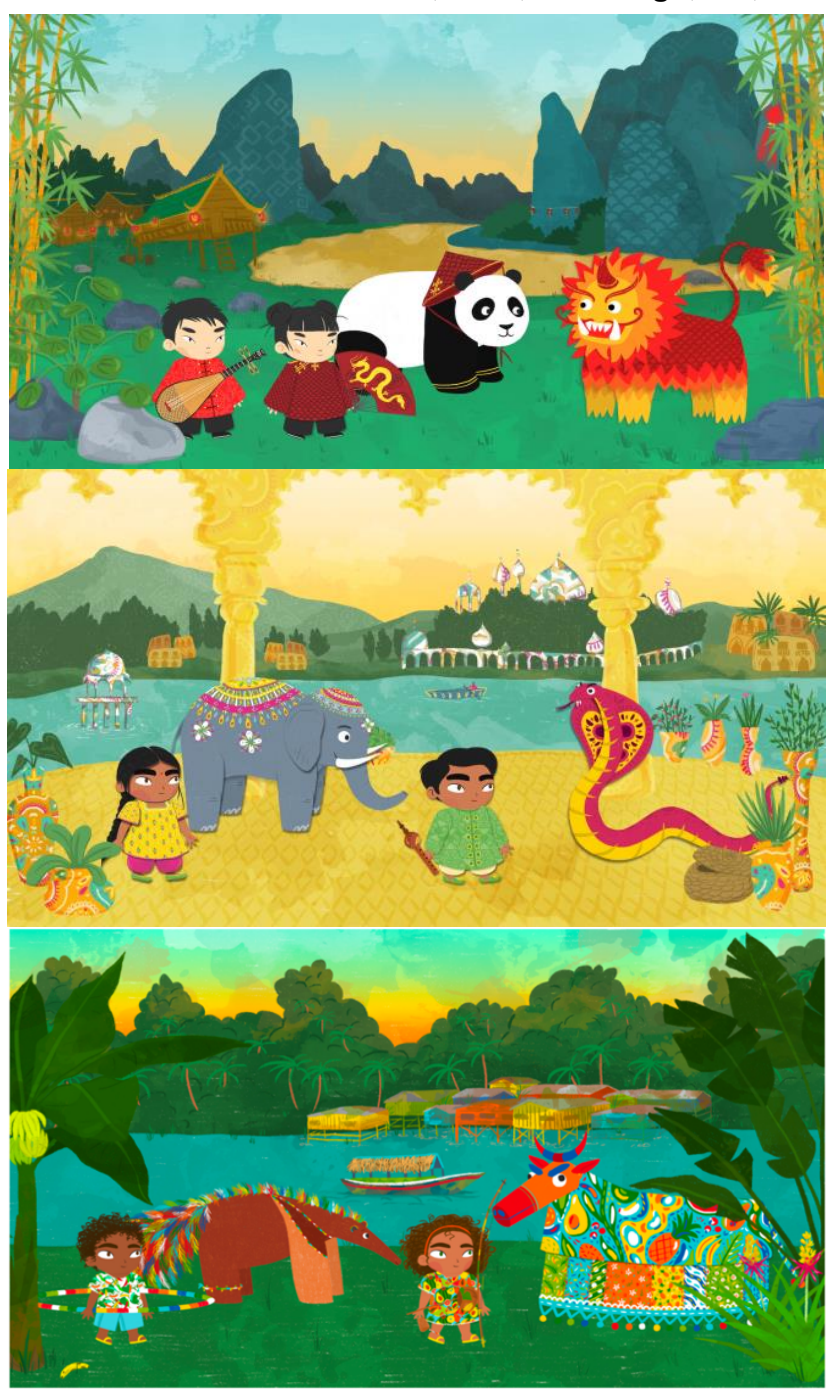

Figure 2 - China, India and Brazil's cultural sets. CGabriela Sá / Mobeybou

\section{Landscapes and Atmospheric-blocks}

The landscapes aim at setting the stage for the narratives, and open the door to the world of imagination. Similar to the design of the other elements, the landscapes avoid representing clichés or stereotypes. The landscapes should themselves invite to the process of storytelling, showing native landscapes embellished with little cultural artifacts of the country that they represent. The atmospheric-blocks (rain, snow, wind, rainbow, night, thunder) allow to further enrich the setting (see Figure 3 and 7).

\section{The Protagonists (Human Characters)}

To promote gender equality and balance, each culture has a feminine and a masculine (human) protagonist, which are furthermore represented with friendly features (reinforced by their roundness), allowing the children to easily identify with these young characters and to acknowledge the role of the hero of their stories. 
Session 8: Creativity with Kids

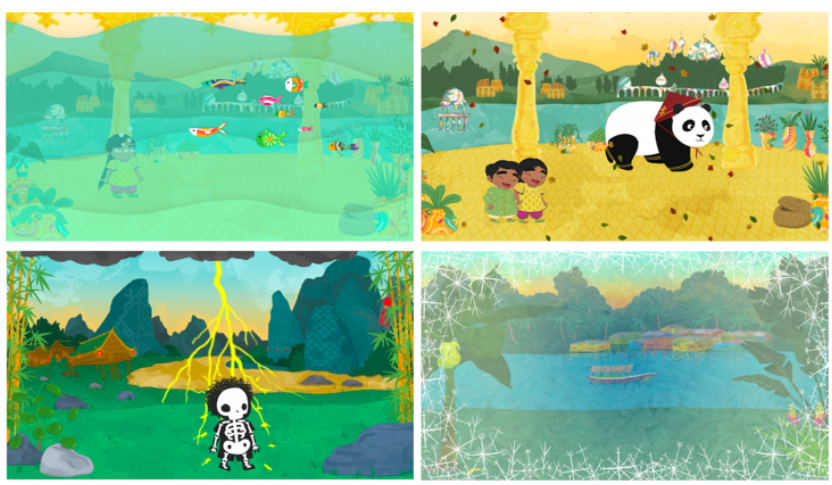

Figure 3 - Effects of the Atmospheric-blocks: flood, which results from the rain-block (top-left); wind: whirls leaves around(top-right); a character is hit by the thunder (bottomleft); snow makes the screen freeze (bottom-right). CGabriela Sá / Mobeybou

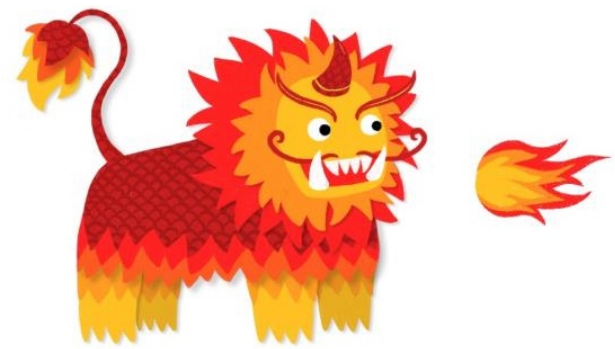

Figure 4 - China's antagonist final design. CGabriela Sá / Mobeybou

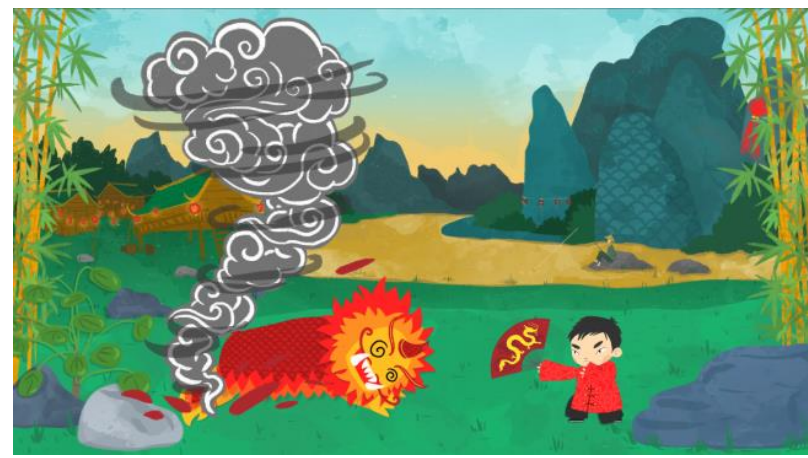

Figure 5 - A Chinese protagonist, uses the fan (magical object) to create a tornado that knocks-out the Chinese antagonist. (C) Gabriela Sá / Mobeybou

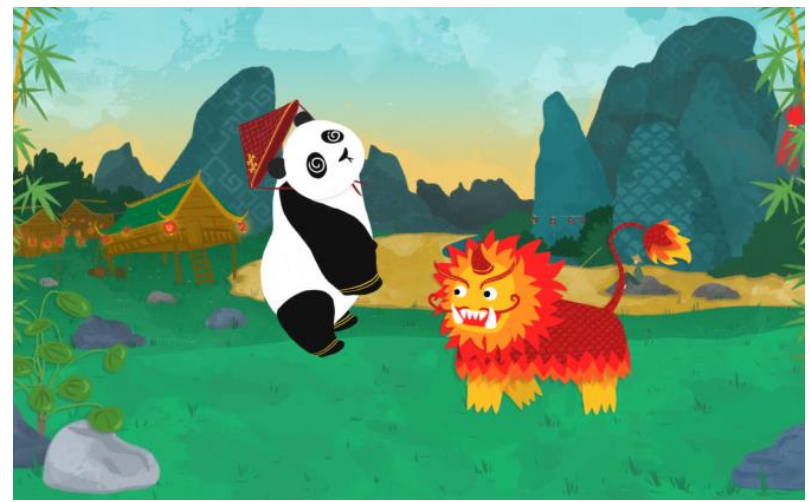

Figure 6 - Outcome of a fight between the Chinese animal and antagonist. CGabriela Sá / Mobeybou
C\&C '19 June 23-26, 2019, San Diego, CA, USA

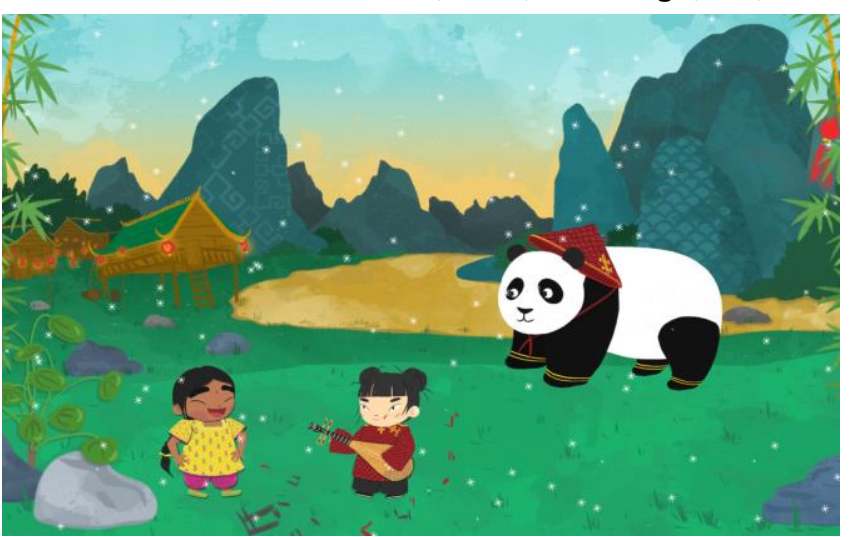

Figure 7 - Indian protagonist and the Chinese giant-panda, listen to the Chinese protagonist playing the pipa, while snow is falling. (CGabriela Sá / Mobeybou

\section{The Animals}

For each culture we tried to choose a representative animal. For example, when choosing the Chinese animal, we have considered several options, such as the golden snub-nosed monkey, the binturong and the tiger. However, our final choice was the panda. This decision was motivated by various reasons: the panda is a native Chinese animal, exclusive to this country (except for the pandas living in captivity in international zoos); it is loved and known worldwide; its conservation status is vulnerable at the moment, and so awareness for its preservation is important for its survival in the wild; it is easily and quickly associated with the Chinese country and culture by audiences everywhere due to mainstream hits like, for example, the Kung Fu Panda trilogy. Finally, pandas' round physiognomy and four-legged stance facilitated the animation process, allowing to create interesting and funny reactions, e.g. it transforms into a ball when attacking an opponent.

\section{The Antagonists}

The design of the antagonists is inspired by the mythical and often scary - creatures of each culture's folklore, traditions and myths. Their design has to convey an air of menace, but still be visually appealing to the children. The creation and design of Nian, the Chinese antagonist (see Figure 4), was inspired by a legend that explains the beginning of Chinese New Year's traditions. Nian was a lioncreature that came down the mountain to attack the villagers every year. One day some children discovered by chance that it was afraid of the red color, and of loudness. From then on, the villagers started to use those elements to protect themselves from him, and now they characterize the Chinese festivities.

\section{The Musical Instruments and the Magical Objects}

These elements are depicted fairly realistically, but when placed on the board, the user sees their magic unfolding on the screen. E.g. the fan creates a tornado that stunts the antagonists (see Figure 5), the Juttis (Indian shoes) make the protagonists float. Both, the objects and the musical instruments have magical properties, and can be used to resolve conflicts between the characters and the antagonists. 


\section{Session 8: Creativity with Kids}

The musical instruments can be used by the protagonists to make all the other "living" elements (on the board) dance and become happy. Similarly, the magical objects can only be used by the protagonists, and help them escape or beat the antagonists. Such magical effects contribute to the creation of a story world, they empower the children to actively influence the story plot and can also inspire the children to create a story around them.

In an effort to avoid stereotypes, and in order to promote the acknowledgement, respect and acceptance of difference, and conveying the idea of social and human equality, we have created equivalent categories for all characters from the different represented cultures. Another way said, there are cultural differences but characters and cultures all have the same human and social status. Crucially, however, is that all the elements from the different cultures can be openly used and mixed to create narratives, therefore welcoming the creative encounter of cultures in the stories.

\section{USER STUDY}

Mobeybou is being developed for being used in informal as well as educational settings. After the first development of the software (comprising India and China cultural sets) we carried out an exploratory user study. The study aimed at:

- Receiving feedback from the children about the system in order to validate and inform future developments;

- Understanding if the manipulation of the system and the interaction rules between de story elements were well thought and easy to understand;

- Assessing if the children were able to recognize the story elements as belonging to other cultures, and if they would refer to these cultures in their storytelling;

- Assessing children's preferred elements and interactions;

- Assessing the teacher's opinion about the system.

\section{Participants}

The study was carried out at a local public preschool, with twelve, eight-years-old children from a class of 3 rd graders. The children were grouped in pairs by the teacher, and had the following composition: group 1 (boy/girl), group 2 (girl/girl), group 3 (boy/girl), group 4 (girl/girl), group 5 (boy/boy), group 6 (boy/boy).

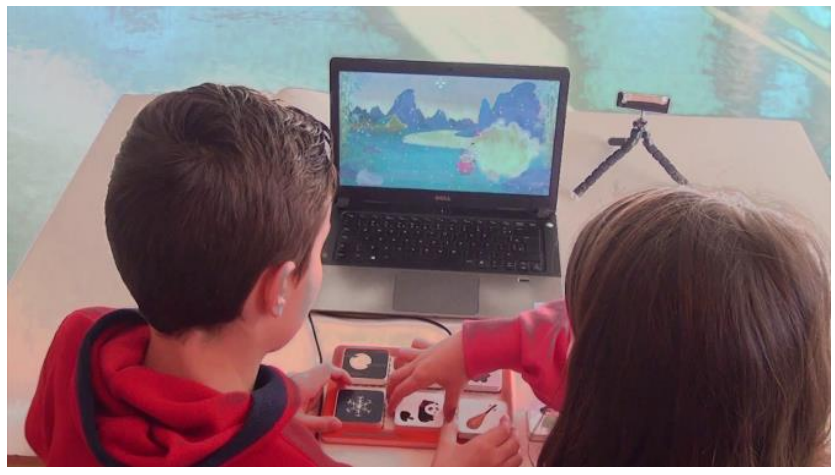

Figure 8 - Two students try out the platform during the pilot study.
C\&C '19 June 23-26, 2019, San Diego, CA, USA

\section{Procedure}

The intervention took place at the school's gymnasium. We equipped the room with two tables and five chairs. Mobeybou was set on a table with the blocks scattered on both sides of the board (see Figure 8). The other table was placed away from the interaction table and used for taking notes. The children came to the room in pairs (one pair at a time). A researcher started by giving a brief explanation of the functioning of the tool. After that each pair interacted with the tool for around 20 minutes. Following the exploratory phase, the researcher asked each pair to tell a story using Mobeybou.

In order to avoid that the children talked to each other about Mobeybou, after the interaction the pair returned to the classroom and called a new pair to the room. However, we could not completely avoid that the pairs briefly talk to each other when leaving / entering the room as they were excited about the activity.

\section{Data Collection}

The data was collected by two researchers (that stood in the background) through observation and written notes. A third researcher accompanied the children in their storytelling. All the interactions were audio-video recorded using a video camera on a tripod with a fixed focus and zoom. The video camera was placed behind the children focusing on the manipulation of the blocks. The videos were later used for qualitative analyses of children's interaction. At the end of each group's interaction, the third researcher carried out a semi-structured interview with each pair of participants. At the end of the intervention she carried out a semi-structured interview with the teacher.

\section{STUDY RESULTS}

Here, we illustrate representative interaction behavior of the children with the tool through seven Vignettes (V1-V7), selected for their frequency and relevance as representative of children' interaction with Mobeybou. The Vignettes focus on three major themes that came up in the analysis: Engagement and Exploration, Creative Appropriation of the Tool and Integration of Multicultural Story Elements. A brief contextualizing text annotates these vignettes.

\section{Engagement and Exploration}

After a brief explanation from the researcher of the functioning of the tool, each pair started by exploring the relations between the story elements, actively placing and removing the blocks from the board. During this free exploration the children often commented on /and called each other attention to the animations that they visualized on the computer's screen. They specially liked to observe the fights between antagonists and animals (see Figure 6); or effects of the different atmospheric blocks (see Figure 3, 7).

Children's engagement was also potentiated by their collaborative exploration and later storytelling. They inspired and built on each other's ideas and actions, and sometimes learned from each other, e.g. one child explained to the other that the boy character was from India. 


\section{Exploring the Relations Between the Elements.}

Vignette 1: A boy placed the lion-block and the snake-block on the board, and observed the screen, saying:

"It looks like they are not friends [they start a fight]. I experimented the snake with the panda and the result was bad, the panda with the lion also resulted badly. From there, there was only a possible conclusion: these two were friends [elephant \& panda] and these two were also friends [lion \& snake]. By looking at what they are doing I concluded that the panda and the elephant are friends because they help each other, and with music they calm down."

Relevance: V1 exemplifies how the children reconstructed a set of actions to understand the relations between certain story elements. They did that by first removing all the blocks from the board and then replicate the action by placing the sequence of blocks on the board. We found relevant the action of stepping back, analyzing and reflecting.

\section{Creative Appropriation of the Tool}

Along the interaction the children creatively appropriated the tool, ingeniously using strategies to adapt the system rules and constraints to their storytelling. For example, most pairs found out that the musical instruments can be used to make all the elements dance as well as to stop or avoid fights. However, some children attributed other affordances to them, as described in V2 - V4.

Vignette 2: "A little girl was playing a pipa (Chinese guitar), and it stopped snowing. [...] Then a panda appeared and all the animals started to appear [a fight starts], but then the girl played the pipa to stop the animals from attacking each other. The girl really wanted to play pipa again and she made the rain stop."

To make this happen in the story, the girl simultaneously placed the pipa-block on the board and removed the rainblock from it.

Vignette 3: "then the wind came and took the elephant away". To make this happen in the story, the pair placed the wind-block on the board and simultaneously removed the elephant-block from it, (making the elephant disappear from the screen).

Relevance: Here we found relevant that the children appropriated the blocks attributing them affordances that were not designed into the system.

\section{Vignette 4:}

"Tiago was playing hide and seek and knocked down a flower pot".

The flowerpot is a decorative element from the Indian landscape.

Relevance: Here we found relevant that the children also incorporated static elements present in the scenario in their storytelling. This made us aware of the potential of such "minor" decorative elements and their potential for promoting creativity and storytelling.

\section{Integration of Multicultural Story Elements}

The children created a total of six stories. Overall, the children mentioned the word China 5 times, the word Chinese 3 times, and the word India 3 times in their stories.

Vignette 5: "Tiago and Nuno went to China, and there they saw a snake and the panda and they got very scared and started fighting, and then Tiago played guitar and the panda and the lion calmed down [...] and then it became morning and Tiago and Nuno left China $[\ldots]$ and went to Portugal.

Vignette 6: "On a full moon night, it was snowing a lot in India".

Relevance: Here we found relevant that the children explicitly placed their stories in China and India.

\section{Narration by "Doing" - Directing, Acting and Watching a Story}

Following the exploratory phase, we asked each pair to tell a story using Mobeybou. We observed that the children took varied and complimentary creative roles along their storytelling. They moved between an external/internal ontological position, operating simultaneously as narrative directors, performers and spectators [46]. As narrative directors the children choose the story characters, the location and the plot. As performers they embodied the characters and became part of the narrative, taking an internal-ontological position. Vignette 4 is an example of a story jointly created by two boys (called Tiago and Nuno). Each of them narrated the actions as being carried out by the other, placing themselves on the stage, "experiencing" several adventures in their storytelling. As spectators, the children step back and take distance looking at the "stage" (external narrative position). This is, they placed the blocks on the board and looked at the screen visualizing the action. For example, the pairs often observed the fight between the animals and the antagonists, giving different opinions about who would be the final winner, sometimes clapping hands and incentivizing their favorite party (as if the animations were living entities). Some children used rich vocabulary in their storytelling and linked the sentences with connectors e.g., "on a full moon night it was snowing heavily". Some explicitly gave an end to their stories.

\section{Children's Perspectives: A tool for Enhanced Creative and Multimodal Storytelling}

At the end of each pair's interaction we carried out a semistructured interview with each pair. We asked them the following questions:

Q1-What for do you think one can use this tool?

Q2- Is the tool useful for telling stories?

Q3- What do you like most in the tool?

Q4- What was your favorite block?

Q5- Is there anything else that you would like to have?

Tables 1-4 depicts children's answers to each of the questions. 
It is for creating stories, we place a block here [board], and we have to talk about that piece

It is for theatre with the pieces, it's also a game. We invent sceneries, stories, and happenings.

It is a Puppet projector, if we place them [blocks] here [board] they appear there [screen].

This are images for us to try to create a story, to give us ideas, and to help us create more creative stories

It is for [making] theatre with the pieces.

It is a Storyteller

It is a Game

Table 1. Q1: What for do you think one can use this tool?

[nodding vigorously with head]: It helps, it helps a lot, we get more ideas.

We have these pieces and when we place landscapes it helps us in the stories. And when we used this block [pipa] it plays music, and we have the music notes, and we have more ideas with these blocks.

It helps us create a story, when we want to create a story, when the teacher tells us to create a story, we have more things in our head.

Table 2. Q2: Is the tool useful for telling stories?

Relatively to Q1 and Q2 we found relevant that the children identified Mobeybou as a tool for scaffolding creativity in multimodal storytelling.

To place the pieces, because they appear on the screen, and always appear the landscapes.

To see "the blocks moving", and to hear the music played by the musical instruments

Table 3. Q3: What do you like most in the tool?

Relatively to Q3 we found relevant that the children liked the multimodality of the toll and to see their actions (carried out with the blocks) extended and augmented into the screen.

Other landscapes (Spain, Brazil, Germany)

More landscapes and we would have other people from other places

There could be more weather, thunder, and more landscapes (at the time we had no thunder block)

Table 4. Q5: Is there anything else that you would like to have?

Regarding Q4 and Q5 the children revealed their preference for many of the story elements, but surprisingly the preference for the landscapes and the atmospheric-blocks was dominant. Interestingly many expressed the wish to have more scenarios and people from other countries. This may indicate an interest and openness to learn about different countries and cultures.

\section{Informal Interview with the Teacher}

At the end of the intervention the teacher came to the room, and we demonstrated the functioning of the tool. The teacher was very positive about the potential of Mobeybou for promoting language and narrative competences, knowledge of the world, and promotion of multiculturalism. She underlined the importance of the teacher as mediator in the use of the tool to attain specific learning results. As an example, she mentioned that she would select the blocks for a certain activity instead of giving the children all the blocks.

\section{DISCUSSION}

The blocks acted as anchors for the creative process potentiating collaboration, which in turn triggered mutually inspired new ideas. The children acknowledged and valued the multimodality mediated by the blocks (objects), which triggered embodiment (active use of their arms, hands, eyes and ears) extending and augmenting their actions into the screen.

They enjoyed visualizing and hearing the elements and the interactions between them and envisioned storytelling with Mobeybou as a playful activity comparing it to a game. Some associated their storytelling with a theatre play, putting themselves on the stage, as illustrated in V5. Such association of the storytelling activity with a theatre play is a good metaphor to convey the different roles (director, performer and spectator) that emerged within the activity, thus bringing strong evidence to our conception of Mobeybou as promoting creative narration by doing. Together, these different roles that the children can embody enable them to carry out a "cognitive dance" of "diving in" and "stepping back", which provides opportunities for reflecting on the storytelling activity. Ackermann [1], calls it Learning as a conversation with artifacts, explaining that "People learn by switching roles from being producers to being critics, from being actors to being audiences, from holding the stage to moving into the background" [1:4]. "Like a good conversationalist, a well-designed object is one that 'knows' how many surprises and wonders contribute to capture people's imagination" [1:7].

The children seem also to be aware of the importance of the landscapes for setting the stage (this may also be indicative of children's knowledge about the structure of a narrative), and open their minds to a novel world. The children found the landscapes representing the Indian and the Chinese cultures intriguing and related them with distant spaces and ambiences. They recognized the characters as original from these cultures and naturally integrated them on their storytelling. They expressed the wish to have more landscapes, and explained that there would also be more characters from other cultures for their stories, widening their 
Session 8: Creativity with Kids

story worlds. This attitude to meet other cultures and the embodiment of characters from other cultures seem to confirm Mobeybou's potential to enhance children's openness towards others, potentially contributing to promoting multicultural and cross-cultural learning.

\section{Limitations and Future Developments}

Some critical areas also emerged in the pilot study, clearly pointing into areas of future development. There is a danger that the children lose the narrative thread among all the narrative stimuli given by the different elements as well as by the open-endedness of the tool. We realized, therefore, that there is a critical need to develop a strategy that might guide the children in the improvement of their story making. In order to support such improvement, the use of the audio recording function that is integrated in Mobeybou, can be useful to record children's stories, and used, among other functions, for self- monitoring as well as for assessing the children's learning curve along time.

Another critical area was children's lack of cultural knowledge. We have realized that it is important to teach them new vocabulary, or to give them information about the different cultures and elements. This gave us a valuable hint to develop a complementary app to grow children's knowledge and inform them about the different cultures, this way adding to the potential of the "building blocks" to construct their narratives (see below). The teacher further referred the need to organize and to limit the blocks used to create a certain story about a certain theme.

\section{ONGOING AND FUTURE WORK}

Presently, we are carrying out studies with Mobeybou, in two elementary schools in Portugal and Denmark. Ongoing and future work includes the development of new hardware, where the blocks connect to each other and send the information to the computer/tablet via Bluetooth, triggering the corresponding digital content on the device's screen. As well as the development of a story app for each culture. The app presents a story and information about the culture, e.g. countries mostly associated with each culture and their location, games involving local traditions, food or other elements that belong and inform about each specific culture. This way informing the children about the different cultures in a playful way, at the same time nourishing their creativity. Besides, in the future work we will develop sets for Northern European, African and Central American culture.

Regarding the evaluation of children's stories, we plan to carry out further user studies where we can measure the introduction of multicultural elements in children's stories, as well as their degree of creativity with two groups in two different conditions.

\section{CONCLUSION}

The preliminary findings of the pilot study carried out with a first prototype of Mobeybou have brought strong evidence to the potential use of the digital manipulative in the promotion of creative multicultural and cross-cultural storytelling
C\&C '19 June 23-26, 2019, San Diego, CA, USA

through collaboration, embodied and multimodal meaning making. It also provided valuable insights for future developments and showed the limitations from the present system. We empathize with [38]: "Every child is born with immense natural talents. How they develop has much to do with the environment in which they are raised and the opportunities they are given".

\section{ACKNOWLEDGMENTS}

We thank and acknowledge the comprehensive revision and suggestions given by the Reviewers and the Associate Chairs that have contributed to significantly improve the quality of this paper. We also thank the school EB1 São Mamede, the students and the teacher Ana Bizarro. This work has been funded by national funds through the Portuguese Foundation for Science and Technology- FCT, grant: SFRH/BPD/111891/2015, and by the European Regional Development Fund (FEDER) through the Competitiveness and Internationalization Operational Program (POCI) under the reference POCI-01-0145- FEDER-032580.

\section{REFERENCES}

[1] Ackermann, E. Experiences of Artifacts: People's Appropriations / Objects' 'Affordances', in: Keyworks in Radical Constructivism. Ernst von Glasersfeld. (M. Larochelle, Ed). Rotterdam, Taipei, Sense Publishers (2007), pp. 249-259.

[2] Ananiadou, K., Claro, M. 21st Century Skills and Competences for New Millennium Learners, in $O E C D$ Countries, OECD Education Working Papers, No. 41. OECD Publishing, Paris, 2009. http://dx.doi.org/10.1787/218525261154.

[3] Bhabha, H. Cultural Diversity and Cultural Differences. The Post-Colonial Studies Reader, ed. B. Ashcroft, G. Griffiths, H. Tiffin, Routledge. New York (2006), pp. 155-157.

[4] Brosterman, N. Inventing Kindergarten. New York: Harry N. Adams Inc, 1997.

[5] Bruner, J.S. The narrative construction of reality. Crit. Inquiry 8 (1) (1991), 1-21 http://dx.doi.org/10.1086/448619

[6] Bruner, J.S. and Haste, H. (Eds.). Making Sense: The Child's Construction of the World. Methuen, London, 1987.

[7] Catala, A.B., Theune, M., Gijlers, H. and Heylen, D. Storytelling as a Creative Activity in the Classroom. In Proceedings of the International Conference on Creativity and Cognition (2017).

[8] Churchill, E. F. Material Experience Research Evidentiary Encounters with Creativity. In Proceedings of the International Conference on Creativity and Cognition (2017).

[9] Cope, B. and Kalantzis, M. New Learning. Elements of a science of education. (2nd ed.). Australia: Cambridge University Press, 2012. 


\section{Session 8: Creativity with Kids}

[10] Dede, C. Immersive interfaces for engagement and learning. Science 323, 5910 (2009), 66-69.

[11] Florida, R. The Flight of the Creative Class, The New Global Competition for Talent. Harper Business, 2006.

[12] Glenberg, A. M. Embodiment as a unifying perspective for psychology. WIREs Cognitive Science 1. John Wiley \& Sons, Ltd (2010), 586-596.

[13] Hao, C., van Boeijen, A. and Stappers, P. J. Cultura: A communication toolkit for designers to gain empathic insights across cultural boundaries. In Proceedings of the IASDR Conference RE: Research (2017), 497-510. doi.org/10.7945/C2SD5J.

[14] Harley, D., Chu, J.H., Kwan, J. and Mazalek, A. Towards a framework for tangible narratives. In Proceedings of the 10th International Conference on Tangible, Embedded, and Embodied Interaction, TEI '16. ACM Press, NY, New York, (2016).

[15] Hornecker, E. A Design Theme for Tangible Interaction: Embodied Facilitation. H. Gellersen et al. (Eds.). In Proceedings of the Ninth European Conference on Computer-Supported Cooperative Work. Switzerland: Springer International Publishing (2005), 18-22.

[16] Hornecker, E. and Buur, J. Getting a Grip on Tangible Interaction: A Framework on Physical Space and Social Interaction. In Proceedings of the Conference on Human Factors in Computing Systems. New York: ACM Press (2006), 437-446.

[17] Ishii, H. and Ullmer, B. Tangible bits: Towards seamless interfaces between people, bits and atoms. In Proceedings of the Conference on Human Factors in Computing Systems. New York: ACM Press (1997), 234-241.

[18] Kegan, R. The Evolving Self. Cambridge, MA: Harvard University Press, 1982.

[19] Kosslyn, S. M. Image and Brain. The Resolution of the Imagery Debate. Cambridge, Massachusetts: MIT Press, 1994.

[20] Kress, G. Multimodality: A Social Semiotic Approach to Contemporary Communication. London, New York: Routledge, 2010.

[21] Lakoff, G. and Johnson, M. Philosophy in the Flesh: the Embodied Mind \& its Challenge to Western Thought. New York, NY: Basic Books, 1999.

[22] Lave, J and Wenger, E. Situated Learning: Legitimate Peripheral Participation. Cambridge: Cambridge, University Press, 1991.

[23] Lotherington, H. Elementary language education in digital multimodal and multiliteracy contexts. In: S. Thorne and S. May (eds.), Language Education and Technology, 3rd ed. New York: Springer (2017), 1-15. doi: 10.1007/978-3-319-02328-1_7-1.

[24] Malaguzzi, L. History, ideas and basic philosophy: An interview with Lelli Gandini by Loris Malaguzzi. In C. Edwards, L. Gandini, \& G. Forman (Eds.), The hundred languages of children: The Reggio Emilia approachAdvanced reflections (2nd ed.). Norwood, NJ: Ablex, 1998.
C\&C '19 June 23-26, 2019, San Diego, CA, USA

[25] Mayer, R. Multimedia Learning: Are We Asking the Right Questions? Educational Psychologist 32, 1. Lawrence Erlbaum Associates, Inc (1997), 1-19.

[26] Montessori, M. The Montessori Method: scientific pedagogy as applied to child education in the "children's houses". Cambridge MA: R. Bentley, 1912.

[27] Moreno, R. and Mayer, R. Interactive Multimodal Learning Environments. Education Psychology Review, 19 - Special Issue on Interactive Learning Environments: Contemporary Issues and Trends. Springer Science (2007), 309-326.

[28] Morrow, L.M. Retelling Stories: A Strategy for Improving Young Children's Comprehension Concept of Story Structure, and Oral Language Complexity. The Elementary School Journal 85, 5 (1985), 646-661.

[29] New London Group. A pedagogy of multiliteracies: Designing social futures. Harvard Educational Review 66 (1996), 60-92.

[30] Paley, V. G. A. The boy who would be a helicopter. Cambridge, MA: Harvard University Press, 1991.

[31] Paley, V.G.A. Child's Work: The Importance of Fantasy Play. Chicago: Chicago University Press, 2004.

[32] Partnership for 21st Century Skills, 2008.

[33] Pinto, G., Tarchi, C. and Bigozzi, L. The relationship between oral and written narratives: A three-year longitudinal study of narrative cohesion, coherence, and structure. Br. J. Educ. Psychol. 85, 4 (2015), 551-569. DOI:10.1111/bjep.12091.

[34] Pinto, G., Tarchi, C. and Bigozzi, L. Development in narrative competences from oral to written stories in five-to seven-year-old children. Early Child. Res. Q. 36 (2016), 1-10. doi.org/10.1016/j. ecresq.2015.12.001.

[35] Resnick, M. Lifelong Kindergarten: Cultivating Creativity through Projects, Passion, Peers, and Play. The MIT Press, Cambridge, Massachusetts, 2017.

[36] Resnick, M., Myers, B., Nakakoji, K., Shneiderman, B., Pausch, R., Selker, T. and Eisenberg, M. Design Principles for Tools to Support Creative Thinking. NSF Workshop Report on Creativity Support Tools (2005), 25-35.

[37] Resnick, M., Martin, F., Berg, R., Borovoy, R., Colella, V., Kramer, K. and Silverman, B. Digital manipulatives: new toys to think with. In Proceedings of the Conference on Human Factors in Computing Systems, ACM Press (1998), 281-287.

[38] Robinson, K. In: Resnick, M. Cultivating Creativity through Projects, Passion, Peers and Play. The MIT Press, Cambridge, Massachusetts, 2017.

[39] Rogers, Y. and Ellis, J. Distributed Cognition: an alternative framework for analyzing and explaining collaborative working. Journal of Information Technology 9, 2 (1994), 119-128.

[40] Ryan, M. L. Beyond myth and metaphor: Narrative in digital media. Poetics Today 23, 4 (2002), 581-609.

[41] Speaker, K. M., Taylor, D. and Kamen, R. Storytelling: Enhancing language Acquisition in Young Children. Education 125, 1 (2004), 3-14. 
Session 8: Creativity with Kids

[42] Trilling, B., Fadel, C. 21st Century Skills: Learning for Life in Our Times. Jossey-Bass, San Francisco, CA, 2009.

[43] Sylla, C., Martins, V., Sá, G., Caruso, A. P., Amaro, B., Menegazzi, D. and Sylla, F. Designing Narrative Learning in the Digital Era. In Proceedings of the ACM International Conference on Human Factors in Computing Systems, CHI'19 Extended Abstracts, May 4-9, 2019, Glasgow, Scotland, UK. New York, NY: ACM Press. doi.org/10.1145/3290607.3312937

[44] Sylla, C., Pereira, I., Zagalo, N. and Brooks, E. t-books a Block Interface for Young Children's Narrative Construction. International Journal of Child-Computer Interaction 18 (2018), 59-66. doi.org/10.1016/j.ijcci.2018.07.002

[45] Sylla, C., Coutinho, C., Branco, P. and Müller, W. Investigating the use of digital manipulatives for
C\&C '19 June 23-26, 2019, San Diego, CA, USA storytelling in pre-school. International Journal of Child-Computer Interaction (2015). doi: 10.1016/j.ijcci.2015.10.001.

[46] Sylla, C., Coutinho, C. and Branco, P. A Digital Manipulative for Embodied "Stage-Narrative" Creation. Entertainment Computing 5, 4 (2014), 495-507. doi.org/10.1016/j.entcom.2014.08.011.

[47] Wilson, R. F. The hand: how its use shapes the brain, language, and human culture. 1998.

[48] Vertovec, S. Towards Post Multiculturalism? Changing Communities, Conditions and Contexts of Diversity. International Social Science Journal 61, 199 (2010), 8395.

[49] Vygotsky, L. S. Imagination and Creativity in Childhood. Journal of Russian and East European Psychology 42, 1 (2004), 7-97. 